ARTÍCULO ESPECIAL

\title{
Mis memorias sobre Robert L. Dressler (1927 - 2019): Botánico y ser humano extraordinario
}

\section{Carlos O. Morales}

Escuela de Biología, Universidad de Costa Rica; carlos.morales1264@gmail.com

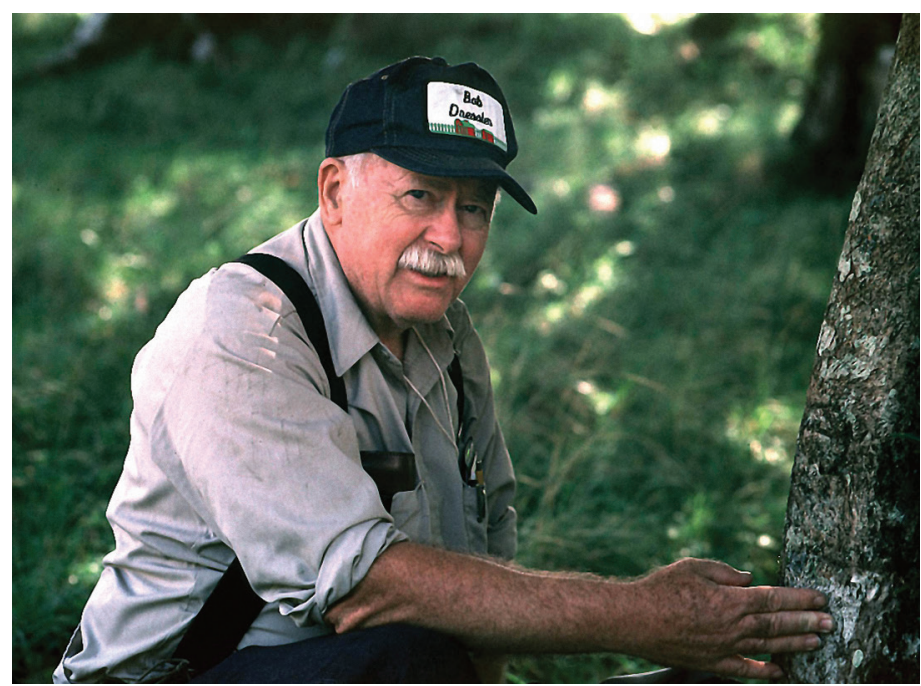

"His life was his work and his work was roaming the tropical forests finding new species of Orchids, Bees and anything else of interest that caught his eye. I will miss his laughter and his Love".

Kerry Radcliffe Dressler, octubre de 2019

A las diez de la noche del martes 15 de octubre de 2019 falleció Robert Louis Dressler en su casa de Cartago, Costa Rica, a la edad de 92 años. Una vida larga llena de logros científicos, de quien durante décadas fue considerado la principal autoridad mundial en el estudio de la sistemática de las orquídeas. Yo sostengo que desde la muerte de Paul C. Standley (1884 - 1963), autor de la primera flora de Costa Rica y estudioso de las floras de otros países de América Central y de México, no perdíamos en esta región a otro botánico tan eminente y famoso como el Dr. Dressler.

La primera vez que lo vi fue en 1984, entrando al edificio de la Escuela de Biología de la Universidad de Costa Rica (UCR) en San José. Recuerdo que varios administrativos y docentes lo saludaron de inmediato, le dirigieron algunas palabras, le preguntaron cómo le había ido en el campo y, sobre todo, le prestaron mucha atención. Allí pude ver que se trataba de una persona muy querida, que al mismo 
tiempo se comportaba con una gran humildad. Del campo llegó con la ropa y los zapatos sucios y con un machete en la cintura, como un campesino costarricense. Esa vez él traía en sus manos una orquídea grande, que había recolectado. Yo era entonces un principiante en la carrera de Biología; todavía no sabía nada, ni siquiera el nombre de ese personaje extranjero de aspecto agradable, con una voz muy sonora hablando un español notablemente bueno. Años después me hice botánico, conocí al Dr. Dressler y a su esposa inseparable, Kerry Radcliffe Dressler, con quienes tuve la oportunidad de viajar en busca de orquídeas y otras plantas. En Costa Rica y otros países latinoamericanos muchos lo llamábamos Doctor Dressler, con respeto, o familiarmente Robert o don Roberto; sus amigos y colegas anglosajones lo llamaban Bob.

El Dr. Dressler nació el 2 de junio de 1927 en una zona rural empobrecida de las montañas Ozark, Misuri, EE.UU. Eran tiempos difíciles debido a la gran depresión de la economía estadounidense y mundial, como señala Kerry en su biografía (Dressler, 2019). Ella conserva una foto que muestra a un niño muy rubio de cinco años, rodeado por dos cabras. En la finca del padre se empezó a gestar ese espíritu curioso y observador de la naturaleza, que lo convertiría en un científico sobresaliente. El niño asistió a la pequeña escuela local unidocente ("one room school") (Fig. 1). Nadie podía ni siquiera sospechar en aquella época, que de esa humilde escuelita saldría un genio de la scientia amābilis (botánica), que en el futuro sería admirado, premiado y homenajeado en muchos países. Cuando tenía 10 años de edad, su padre murió trágicamente; su madre decidió migrar hacia California, porque sola no podía hacerse cargo de la finca y, además, quería estar cerca de su familia (Dressler, 2019). Robert decía en broma que nació en la sierra de Ozark, pero salió a la civilización en California (Dressler \& Higgins, 2003). En 1945 el terminó la secundaria y se alistó en el ejército de los EE.UU. en los últimos meses de la Segunda Guerra Mundial. El ejército lo entrenó para dar de baja a los soldados que retornaban a casa desde los frentes de batalla en el extranjero. En su currículum en lengua española él anotó: "1945-1946. Oficinista de finanzas, Ejército de E.U.A.".

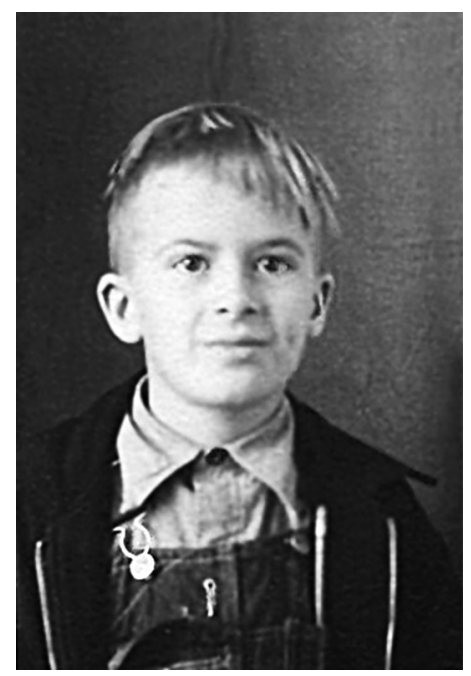

Fig. 1. Robert con 8 años de edad. Fig. 1.8 years old Robert.

En 1946 Robert hizo una solicitud y fue aceptado en la University of Southern California (USC), a donde ingresó tras finalizar su carrera en el ejército. Como relata Kerry, en la adolescencia él tuvo contacto con un zoológico privado, donde fue atraído por las serpientes, y ya en la universidad matriculó primero un curso de zoología, pero no lo satisfizo. En el segundo semestre matriculó un curso de botánica y a partir de allí fijó su interés en esta rama de la biología. Su profesor de botánica estudiaba Euforbiáceas y motivó a Robert para recolectar especímenes para el herbario universitario. Ya en la secundaria él había estudiado español y aprovechó que tenía vecinos mexicanos, de modo que cuando fue a recolectar plantas en Baja California sus conocimientos de español le fueron muy útiles (Dressler, 2019). Con el tiempo llegaría a tener un gran dominio de este idioma.

En 1951 obtuvo un Bachillerato en Botánica de la USC y de allí pasó a la Universidad de Harvard, donde se graduó de Doctor 
en Biología en 1957. Su Tesis de Doctorado fue sobre el género Pedilanthus [nombre que actualmente se considera sinónimo de Euphorbia (Euphorbiaceae)]. Durante sus estudios doctorales hizo viajes de recolecta a México para el Gray Herbarium de Harvard y desde entonces mostraba un gran interés por las orquídeas, asistiendo a las reuniones de la American Orchid Society, que en aquella época tenía su sede en Boston, en la Universidad de Harvard (Dressler, 2019).

En 1958 Robert salió de Harvard para trabajar en el Jardín Botánico de Missouri como taxónomo y editor de la prestigiosa revista Annals of the Missouri Botanical Garden. También fue profesor en la Escuela de Botánica Henry Shaw de la Washington University en San Luis, Missouri, hasta 1963. En ese año hizo un viaje de recolecta a Panamá con Calaway Dodson, otro orquideólogo eminente. Allí se reunieron con el Dr. Martin Moynihan, quien estaba buscando candidatos científicos para trabajar en una estación biológica en la isla Barro Colorado de ese país. En agosto de 1963 Robert se estableció en la estación, que posteriormente se convirtió en el prestigioso Smithsonian Tropical Research Institute (STRI).

En 1975 Robert conoció a Kerry en Panamá, quien sería su compañera inseparable el resto de su vida (44 años). Cuando se conocieron, ella estaba trabajando con mariposas; después, cuando empezaron a ir al campo juntos, Robert le propuso que tomara fotos para él, a fin de concentrarse en la búsqueda de plantas. Con la práctica y el estudio de las artes fotográficas, ella se convirtió en una fotógrafa experta. La pareja se casó el 2 de junio de 1977 en Selby Gardens, Florida; fue el día en que él cumplió 50 años de edad (Dressler, 2019).

En 1984 Dora Emilia Mora de Retana, directora del Jardín Botánico Lankester en Cartago, lo invitó a ofrecer un Curso de Orquideología en la Escuela de Biología de la UCR (San José). Él viajó con su familia desde Panamá en un medio año sabático. Vale aclarar que el Dr. Dressler había estado numerosas veces en Costa Rica, en contacto con botánicos como Rafael Lucas Rodríguez desde la década de
1960 (Dressler, 1986; Dressler, 2019). En aquel entonces ya estaba trabajando en una guía de orquídeas, que sería una realidad después de retirarse de STRI en 1986: "Field Guide to the Orchids of Costa Rica and Panama" (Cornell University Press, 1993). En sus visitas a Costa Rica, uno de sus lugares preferidos para buscar orquídeas eran las montañas de Monteverde (Fig. 2).

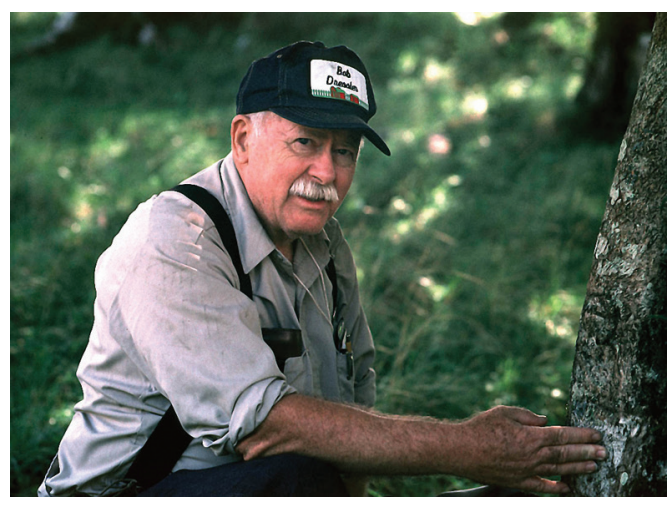

Fig. 2. El Dr. Dressler en Monteverde, Costa Rica.

Fig. 2. Dr. Dressler in Monteverde, Costa Rica.

En 1985 la familia se mudó de Panamá a Florida, en vista de que Robert aceptó un puesto en la Universidad de Florida en Gainesville para escribir un libro sobre las especies de plantas de humedales de Florida. Así, el botánico y la fotógrafa recorrieron todos los humedales de Florida y los estados vecinos Georgia y Alabama. Un reto nuevo, según Kerry, pero uno que a él le gustó. En 1993 él me contó que su salida de Panamá se debió, también, a la llegada al poder del dictador Manuel A. Noriega en 1983 y a los rumores sobre la inminente invasión de ese país por tropas estadounidenses para derrocar a Noriega, lo que sucedió en 1989. Aunque Robert había sido funcionario militar, en esa ocasión me dijo con gran pesar que él no estuvo satisfecho con la forma en que se dio la invasión, en que murieron (agrego yo) cientos de personas inocentes.

Trabajando en la Universidad de Florida como curador asociado del herbario, en 1987 el Dr. Dressler publicó la obra "Identification 
Manual for Wetland Species of Florida". Según su propio currículum vitae, entre 1993 y 2004 trabajó de nuevo para el Jardín Botánico de Missouri, esta vez como curador y editor de los tratamientos de Orchidaceae para dos floras: el "Manual de Plantas de Costa Rica" (vol. III, publicado en 2003) y "Flora Mesoamericana”. Este trabajo lo realizó en el herbario de la Universidad de Florida, pero con frecuentes contactos con sus colaboradores en América Latina.

A inicios de la década de 1990 la fama y el prestigio de este destacado científico no conocían fronteras. En varias ocasiones pude ver la expectativa que causaba su visita al Jardín Lankester o a la Escuela de Biología de la UCR, tanto entre profesores que lo conocían (o habían escuchado sobre él), como entre estudiantes y aficionados a las orquídeas. En 1993 una estudiante alemana, de intercambio en la UCR, recibió de manos del Dr. Dressler la versión alemana autografiada (Die Orchideen. Biologie und Systematik der Orchidaceae) de su famoso libro "The Orchids. Natural History and Classification" (Harvard University Press, 1981); poco después esta estudiante se acercó para decirme con notable orgullo y en buen español: "iDressler es un apellido alemán!”. $\mathrm{Su}$ libro "Phylogeny and Classification of the Orchid Family" (Dressler, 1993) presenta grandes diferencias en filogenia y clasificación de orquídeas respecto a "The Orchids". En la introducción de "Phylogeny..." se lee (mi traducción): “Cuando acepté publicar The Orchids: Natural History and Classification (1981), me encontré en un dilema y con tiempo muy limitado para decidir. El material sobre historia natural era bueno y relativamente fácil de tratar, pero yo tenía que decir algo sobre clasificación de orquídeas. La clasificación tradicional era artificial, pero no estaba claro qué hacer para mejorar el sistema...". En seguida menciona decisiones que tomó en 1981 sobre afinidades de grupos, que ya en la década de 1990 se consideraban erróneas. Algo muy interesante: él señala que a inicios de la década de 1980 muchos botánicos profesionales tendían a evitar las orquídeas, hasta el extremo de que uno de ellos dijo: "Yo no presto atención a las orquideas; solo se las doy a Garay" [Se refería a Leslie Garay (1924-2016), otro experto estadounidense en Orchidaceae]. De esta manera el Dr. Dressler dio a entender que en aquel entonces se sintió muy solo al tomar decisiones sobre filogenia de orquídeas, pero él mismo indicó que en la década siguiente empezaron a aparecer más tesis y publicaciones sobre estas plantas.

En marzo de 1993 viajé con Dora Emilia Mora y los Dressler a Jericó de Desamparados (1700 m) y Tarbaca de Aserrí (1 $800 \mathrm{~m}$ de altitud), muy cerca de mi natal Rosario de Desamparados. Este viaje, aunque fue de un solo día, quedó fuertemente grabado en mi memoria. En las primeras horas de la tarde estábamos en un bosquecillo de Tarbaca, al lado de un potrero. Kerry había permanecido sentada en el vehículo, mientras los demás buscábamos orquídeas, sobre todo terrestres. En un momento el Dr. Dressler se acercó a Kerry y le preguntó algo en pocas palabras. Me pareció que él estaba preocupado de que ella estuviera aburrida, pero escuché claramente la respuesta de ella: "We're enjoying a wonderful day" (Estamos disfrutando de un día maravilloso). Ella tuvo razón; ese fue un día espléndido, también para mí, en mis queridas montañas acompañado de personas muy especiales, con paisajes hermosos, cielo despejado y una temperatura entre 24 y 25 ${ }^{\circ} \mathrm{C}$. Tanto en Jericó como en Tarbaca, el Dr. Dressler recolectó una pequeña orquídea terrestre, con flores pero sin hojas, que vio primero en Jericó desde el vehículo en marcha (ipero los demás no la vimos!). Fueron solo dos especímenes, que yo preparé para herbario, y flores en líquido. Poco tiempo después él envió unas flores de esas plantas a Dariusz Szlachetko en Polonia, quien ya destacaba como estudioso de las taxonómicamente difíciles orquídeas terrestres tropicales, y en 1996 describió la especie como Schiedeella dressleri Szlach. El espécimen de Jericó se halla en el Herbario de la Universidad de Costa Rica (D.E. Mora et al., USJ-48447). Esta fue otra virtud que reconocí en el Dr. Dressler: aun siendo en las décadas de 1980 y 1990 la principal autoridad 
mundial en orquídeas, él no se consideró nunca el único experto. Una vez le escuché decir que él no conocía bien los géneros de orquídeas terrestres; por eso no me sorprendió que solicitara ayuda al botánico polaco. En otra ocasión, después de que comentamos sobre un joven botánico estadounidense que había recolectado orquídeas en Costa Rica y sorprendentemente había puesto nombres científicos completos (género más especie) a todos los especímenes, el Dr. Dressler me dijo: "Los jóvenes botánicos, cuando apenas comienzan, creen que pueden identificar todas las especies". Así, la buena taxonomía requiere de cierta madurez y experiencia; esta fue una buena enseñanza para el resto de mi vida profesional. Unos minutos de conversación o una gira al campo con el Dr. Dressler fueron para mí (así como para muchos otros estudiantes) mejores que cien clases teóricas.

En noviembre de 1993 viajamos los Dressler, Barry E. Hammel (quien conducía un vehículo de la UCR, con permiso de Dora Emilia Mora) y yo desde San José hasta la Península de Osa. El viaje duró cinco días e hicimos múltiples estaciones para ver y recolectar plantas. En la península nos hospedamos en una casa de Rancho Quemado, donde nos sirvieron una cena deliciosa con palmito silvestre. Justo después de la cena nos trajeron café en vasos de cristal y un frasco con azúcar, pero sin cucharas para servirse y mezclar el azúcar. Yo estaba preocupado por eso, mientras los Dressler y Barry discutían acaloradamente en un inglés rápido y muy coloquial (según el propio Dressler), que yo no podía entender. En un momento le dije al Dr. Dressler: "¿Qué problema! Veo que no nos trajeron cucharas para el azúcar". Él reaccionó de inmediato y al tiempo que tomaba en su mano el tenedor que había usado para cenar me dijo: "iNo importa!", movió el café con el tenedor y continuó con la charla vivazmente. Así de práctico, espontáneo y humilde era este gran señor. En la península recolecté Sigmatostalix brownii Garay (C.O. Morales 737, USJ) por primera vez en bosque primario; esta joya en miniatura impresionó al Dr. Dressler, quien la reconoció de inmediato porque la había visto en Panamá. En un bosque tristemente devastado por madereros, un tronco talado y caído tenía una planta de Epidendrum hellerianum A.D. Hawkes, que el Dr. Dressler no había visto hasta entonces en Costa Rica (pero la única planta vista y recolectada era estéril y así murió en cultivo en el Jardín Lankester). En el viaje de regreso paramos brevemente en la parte más alta de la Carretera Interamericana, en el Cerro de la Muerte. En una pequeña charca junto a la carretera, Barry halló plantitas de una especie que no habíamos visto nunca: Crassula aquatica (L.) Schönland (Crassulaceae) (B.E. Hammel et al. 19158, CR, $\mathrm{MO})$. Este fue el primer registro tanto del género como de la especie en Costa Rica (Missouri Botanical Garden, 2020).

Jorge Warner, Franco Pupulin, ambos del Jardín Botánico Lankester, y Carlos Ossenbach sugirieron al Dr. Dressler establecerse en Costa Rica para laborar en ese jardín. Él aceptó y viajó con Kerry a Costa Rica en marzo de 2005 (Dressler, 2019). En marzo de 2006 ofreció una conferencia magistral para la Cátedra Rafael Lucas Rodríguez, titulada "Historia natural y conservación de las orquídeas" (auditorio de la Ciudad de la Investigación, UCR). Sus últimos años laborales (2005-2015) los pasó en el Lankester como Coordinador de Investigación y en la Escuela de Biología de la UCR como Profesor Visitante, ocupado especialmente con el estudio del difícil género Sobralia (flor de un día), de flores a menudo grandes y hermosas, pero muy delicadas, que no se conservan bien secas ni en líquido preservante (Fig. 3). El Dr. Dressler sostenía que era necesario cultivar esas plantas y observarlas vivas, porque con material de herbario no podía hacerse buena taxonomía de Sobralia. Para facilitar su trabajo, la pareja se estableció en una casa pequeña y sencilla, a muy corta distancia a pie de la entrada del jardín. Además, ambos adquirieron la nacionalidad costarricense por naturalización. Antes de retirarse en 2015, el Dr. Dressler fue Director del Jardín Lankester durante seis meses, hasta que llegó Mario A. Blanco a ocupar ese puesto. La presencia y el trabajo del Dr. Robert L. Dressler en el Lankester durante 


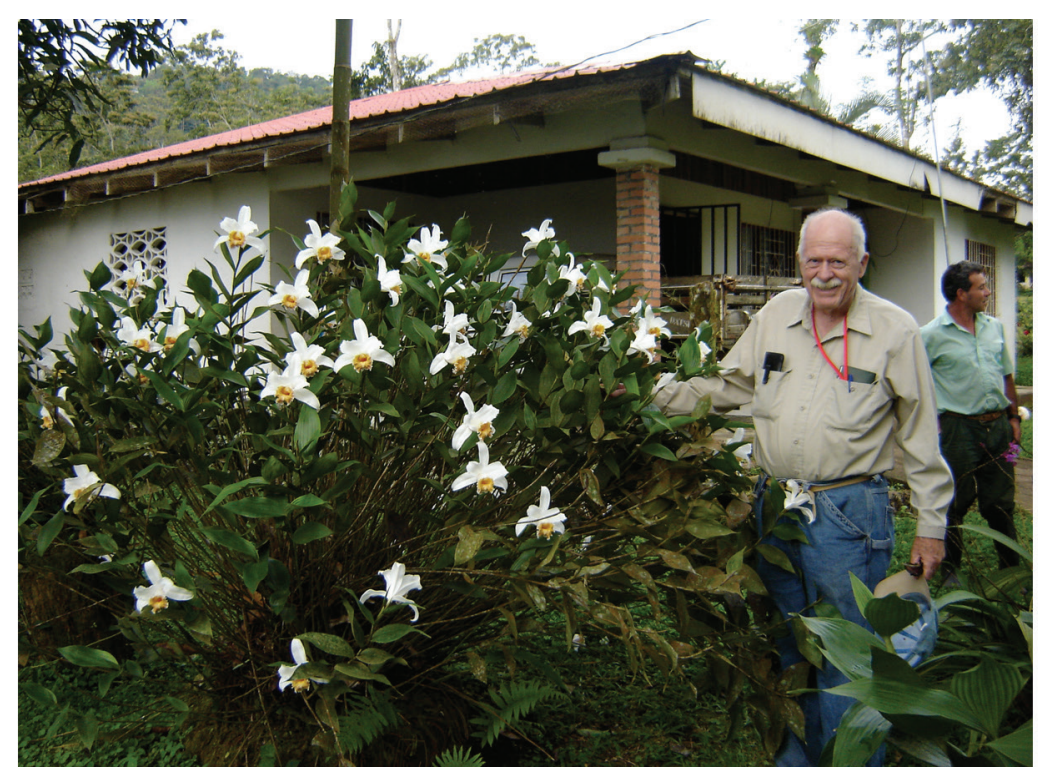

Fig. 3. El Dr. Dressler con una enorme planta de Sobralia chrysostoma Dressler en Costa Rica, 2014.

Fig. 3. Dr. Dressler with a big plant of Sobralia chrysostoma Dressler in Costa Rica, 2014.

10 años elevaron sustancialmente el prestigio internacional de este centro de investigación, dedicado principalmente a las orquídeas. En 2016 él fue reconocido como Profesor Emérito de la Universidad de Costa Rica.

¡Cuán agradable era conversar con el Dr. Dressler y cuántas historias y anécdotas tenía para contar! La gente disfrutaba mucho escuchando sus historias, ya que él tenía un humor muy especial. Una vez nos contó de su estancia en una reserva indígena de Panamá, en la década de 1960 o 1970. Allí estuvo en medio de un grupo de indígenas que todavía usaban taparrabo y, en apariencia, eran muy naturales. En un momento dado de la conversación fue necesario hacer un cálculo numérico. “¿Cuánto es...?", preguntó alguien. Con toda seriedad, uno de los indígenas se sacó una calculadora electrónica del taparrabo e hizo el cálculo sin problemas. En 2007 envié fotos al Dr. Dressler de una planta de Sobralia cultivada en el corredor de una casa de Cariari de Pococí (bajura atlántica de Costa Rica); él me contestó de inmediato que le parecía una especie nueva muy interesante. Por eso en febrero de 2008 viajé con mis amigas y colegas Fabiola
Jiménez (autora de las fotos) y Virginia Aguilar a esa localidad, pero tuvimos mala suerte: una cabra se había comido las hojas de la única planta conocida, que lucía muy mal y hasta tenía un gusano nematodo grande y azul en las raíces podridas. Nos regalaron la planta, la desinfecté y cultivé con mucho cuidado en un invernadero de la Escuela de Biología de la UCR, pero aun así murió cerca de un año después, sin haber florecido. Cuando le comenté al Dr. Dressler el final de esta historia, su respuesta divertida fue: “iQué lástima, Carlos! De todos modos las Sobralias son muy complicadas, con o sin cabras".

Una vez él se rió mucho contándome que después de haber estado un tiempo en Austria y Alemania, sentía que ya entendía bastante bien el alemán. Aun así, cuando le preguntaban si hablaba alemán, él siempre contestaba: “ $J a$, aber sehr wenig" (Sí, pero muy poco). Él pronunció como los bávaros la erre de sehr muy sonora (mientras la mayoría de alemanes pronuncia \pm "séa"). Entonces emprendió un viaje a Suiza, donde se sorprendió por no entender casi nada. Por lo visto, el Dr. Dressler desconocía que el dialecto suizo es muy diferente al alto 
alemán (Hochdeutsch). A mediados de la década de 2000 yo estaba en el Herbario USJ con el Dr. Dressler y un eminente orquideólogo europeo, quien refiriéndose a la filogenia molecular con base en ADN dijo: "Es una maravilla. ;Es como magia!". Sin palabras, hice un gesto de desaprobación y moví la cabeza en señal de negación. El Dr. Dressler observó mi reacción y de modo quizás solidario se rió conmigo, pero en silencio por respeto al colega que estaba de espaldas, con quien definitivamente yo no estaba de acuerdo.

El botánico Faustino Miranda (1905-1964; Miranda, 1963), que emigró a México en 1939 al finalizar la Guerra Civil Española, reveló al final de su vida cuánto admiró las obras del gran botánico Paul C. Standley (a quien conoció en el Field Museum, Chicago), y señaló sobre "el súbito surgimiento de la nación norteamericana, ... que hombres como Standley eran la clave para explicar la posibilidad de ese repentino y casi explosivo desarrollo de una nación. Me imaginaba la inteligencia y energía, medidas en cantidad y calidad de conocimientos acumulados, y la capacidad de dirección y organización necesarias para escribir un libro como 'Trees and Shrubs of México"'. También escribió que lo impresionó el español fluido y correcto de Standley, así como su memoria prodigiosa al contar anécdotas de sus expediciones en América Central y "el sincero cariño que mostraba por los pequeños países centroamericanos". Estas son características que muchos reconocimos después en el Dr. Dressler, de modo que percibo un fuerte paralelismo entre las vidas de Standley y Dressler. Además, igual que Standley en Honduras, Dressler terminó su trabajo y sus días en un país de América Central. Los costarricenses fuimos afortunados, porque los Dressler escogieron a Costa Rica para desarrollar el epílogo de su gran obra orquideológica. Miranda añadió sobre Standley que fue “... un representante legítimo de esas generaciones de hombres enérgicos que hicieron posible el actual encumbramiento (desarrollo) de los Estados Unidos. Al parecer su filosofía se fundaba en la razón y la colaboración, y su estilo era la acción rápida y eficiente". De nuevo me parece como si las palabras de Miranda (un inmigrante español, procedente de una nación devastada por la guerra, deslumbrado por la diversidad vegetal de México y al mismo tiempo por el desarrollo de EE.UU.) se aplicaran de igual modo al Dr. Dressler, quien ya en vida recibió numerosos reconocimientos y homenajes. A lo largo de mi vida profesional he podido constatar cuán sólida y cordial puede ser la comunicación entre científicos estadounidenses y latinoamericanos, mientras con frecuencia políticos y militares de EE.UU. tratan a los latinoamericanos con indiferencia, arrogancia o hasta con manifiesto desprecio.

La Escuela de Biología de la UCR hizo un justo homenaje a la memoria del Dr. Dressler el 25 de octubre de 2019. En este acto, el Decano de la Facultad de Ciencias, Javier Trejos Zelaya, y el Director de la Escuela, Daniel Briceño Lobo, entregaron a Kerry la bandera de la UCR. Además, se exhibieron ejemplares de libros y artículos científicos publicados por el Dr. Dressler, especímenes (del Herbario USJ) de especies de orquídeas recolectadas por él, de especies descritas por él, y de géneros y especies de plantas y abejas (éstas del Museo de Zoología de la UCR) dedicados a él (Fig. 4). Las cifras del legado científico del Dr. Dressler, tal como las resume Pridgeon (2016), son elocuentes y superlativas: describió 12 taxa superiores de orquídeas (tribus y subtribus), 18 géneros de orquídeas, 230 especies de orquídeas, 10 especies de otros grupos de plantas y 38 especies de abejas. Además, publicó 162 combinaciones nuevas de Orchidaceae y 10 de Euphorbiaceae, nueve libros y (entre 1953 y 2018) 252 artículos científicos. Las cifras dadas aquí de especies descritas, libros y artículos publicados difieren de las de Pridgeon. A él le dedicaron seis géneros de plantas floríferas, 41 especies de orquídeas, 50 especies de otras plantas y siete especies de animales invertebrados (incluyendo abejas, una avispa parasitoide y un crustáceo). Una lista de estos taxa se halla en el sitio web de Dressler (2019).

Tengo la impresión de que con la muerte del Dr. Dressler llegó el final de una época en 


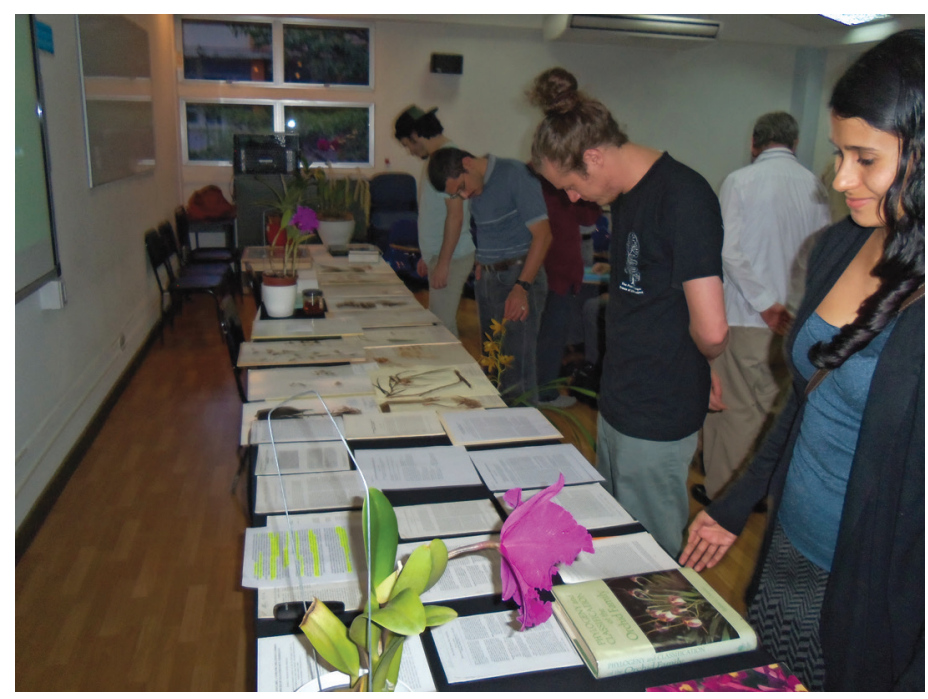

Fig. 4. Homenaje a la memoria del Dr. Dressler. Escuela de Biología, Universidad de Costa Rica, 25 oct. 2019. Foto del autor.

Fig. 4. Tribute to the memory of Dr. Dressler. Escuela de Biología, Universidad de Costa Rica, Oct. $25^{\text {th }}, 2019$. Author's photograph.

que toda la sistemática de plantas seminíferas podía hacerse con rasgos morfológicos, lo que implica sobre todo observación y recolecta en el campo y el invernadero, trabajo con especímenes de herbario y uso de literatura especializada, lupa, estereoscopio y, ocasionalmente, microscopio. Actualmente es poco probable que un estudio sobre filogenia y clasificación de plantas sea ampliamente aceptado si no incluye análisis de secuencias de ADN. Sin embargo, ya en la década de 1990 algunos sistemáticos habían entendido que los datos moleculares no solamente habían confirmado gran parte de la taxonomía tradicional de plantas y permitido corregir errores de interpretación, sino que, además, nunca podrían reemplazar el análisis morfológico en sistemática (cf. Bachmann, 1995). En síntesis, considero que la labor del Dr. Dressler tuvo un gran impacto positivo en muchos orquideólogos y botánicos en general, así como en numerosos estudiantes y aficionados a las orquídeas, especialmente en EE.UU., México, Costa Rica y Panamá. El renombre y el trabajo del Dr. Dressler sin duda fueron cruciales para despertar en muchos el interés en identificar, cultivar, amar y conservar las orquídeas. En 2003 él entró en el Herbario USJ acompañado por el orquideólogo alemán Günter Gerlach; ambos venían del campo y habían estado en contacto con aficionados. Allí el Dr. Dressler me dijo: "Me llaman el abuelo de las orquideas. No sé si eso es bueno". Yo le sonreí y guardé silencio, pero ahora veo claro que uno de sus mayores aportes fue llevar con humildad la ciencia a la gente.

En el Apéndice digital se halla un catálogo de todas las publicaciones del Dr. Dressler (Apéndice digital).

\section{AGRADECIMIENTOS}

Agradezco sinceramente a Kerry Radcliffe Dressler y al colega Mario A. Blanco (USJ) por la información proporcionada. Las fotos de las figuras 1 a 3 son cortesía de Kerry, y según ella la foto de la Fig. 3 fue tomada por Diego Bogarín (Jardín Lankester). El colega Elmer G. García leyó una versión preliminar de este texto e hizo, igual que dos revisores anónimos, sugerencias muy valiosas para mejorarlo. 


\section{REFFERENCIAS}

Bachmann, K. (1995). Progress and pitfalls in systematics: cladistics, DNA and morphology. Acta Botanica Neerlandica, 44(4), 403-419.

Dressler, K.R. (2019). Robert Louis Dressler (1927-2019): A Biologist for All Seasons. Icones Orchidacearum, 17(1), II-XVII. Retrieved from https://www. researchgate.net/publication/336721560_ICONES ORCHIDACEARUM_Fascicle_171_The_Genus Epidendrum_Part_13

Dressler, R.L. (1986). Prólogo. En R.L. Rodríguez, D.E. Mora, M.E. Barahona, \& N.H. Williams (Eds.), Géneros de orquídeas de Costa Rica. San José: Editorial Universidad de Costa Rica.

Dressler, R.L. (1993). Phylogeny and Classification of the Orchid Family. EE.UU., Oregon: Dioscorides Press.
Dressler, R.L. \& Higgins, W.E. (2003). Guarianthe, a generic name for the "Cattleya" skinneri complex. Lankesteriana, 7[3(2)], 37-38.

Miranda, F. (1963). Así vi yo a Standley. En L.O. Williams (Ed.), Homage to Standley: Papers in honor of Paul C. Standley (pp. 23-26). Chicago: Chicago Natural History Museum. Retrieved from https://www.biodiversitylibrary.org/item/49664\#page/29/mode/1up

Missouri Botanical Garden. (2020). Crassula aquatica. Retrieved from http://www.tropicos.org/ Specimen/893094

Pridgeon, A.M. (2016). Robert L. Dressler: A biologist for all seasons (Con fotografías y colaboración biográfica de K.R. Dressler). Orchids Magazine, 126131. Retrieved from https://stri.si.edu/sites/default/ files/a_biologist_for_all_seasons.pdf

Carlos O. Morales

Escuela de Biología, Universidad de Costa Rica; carlos.morales1264@gmail.com

NOTA

La bibliografía del Dr. Dressler aparece únicamente en nuestra edición digital, en https://revistas.ucr.ac.cr/index.php/rbt 